\title{
Atomically Dispersed Copper Sites in a Metal-Organic Framework for Reduction of Nitrogen Dioxide
}

Yujie Ma, Xue Han, Shaojun Xu, Zi Wang, Weiyao Li, Ivan da Silva, Sarayute Chansai, Daniel Lee,* Yichao Zou, Marek Nikiel, Pascal Manuel, Alena M. Sheveleva, Floriana Tuna, Eric J. L. McInnes, Yongqiang Cheng, Svemir Rudić, Anibal J. Ramirez-Cuesta, Sarah J. Haigh, Christopher Hardacre, Martin Schröder,* and Sihai Yang*

Cite This: J. Am. Chem. Soc. 2021, 143, 10977-10985

Read Online

ACCESS | Lill Metrics \& More | 期 Article Recommendations

Supporting Information

ABSTRACT: Metal-organic framework (MOF) materials provide an excellent platform to fabricate single-atom catalysts due to their structural diversity, intrinsic porosity, and designable functionality. However, the unambiguous identification of atomically dispersed metal sites and the elucidation of their role in catalysis are challenging due to limited methods of characterization and lack of direct structural information. Here, we report a comprehensive investigation of the structure and the role of atomically dispersed copper sites in UiO-66 for the catalytic reduction of $\mathrm{NO}_{2}$ at ambient temperature. The atomic dispersion of copper sites on UiO-66 is confirmed by high-angle annular dark-field scanning transmission electron microscopy, electron paramagnetic resonance spectroscopy, and inelastic neutron scattering, and their location is

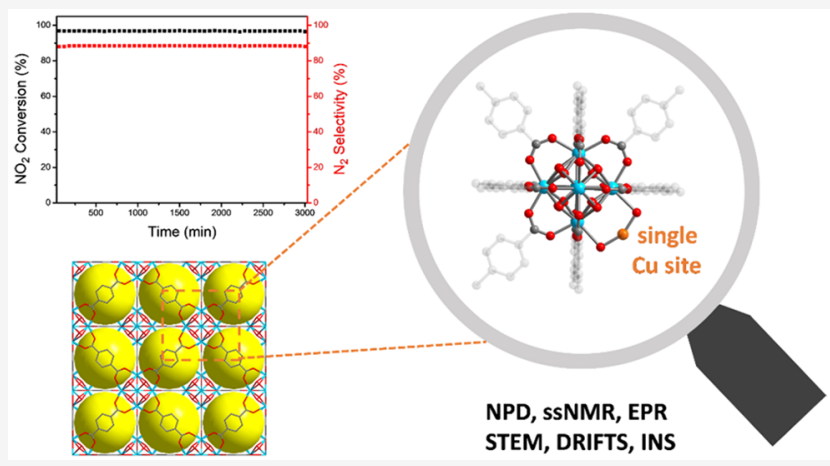
identified by neutron powder diffraction and solid-state nuclear magnetic resonance spectroscopy. The Cu/UiO-66 catalyst exhibits superior catalytic performance for the reduction of $\mathrm{NO}_{2}$ at $25{ }^{\circ} \mathrm{C}$ without the use of reductants. A selectivity of $88 \%$ for the formation of $\mathrm{N}_{2}$ at a $97 \%$ conversion of $\mathrm{NO}_{2}$ with a lifetime of $>50 \mathrm{~h}$ and an unprecedented turnover frequency of $6.1 \mathrm{~h}^{-1}$ is achieved under nonthermal plasma activation. In situ and operando infrared, solid-state NMR, and EPR spectroscopy reveal the critical role of copper sites in the adsorption and activation of $\mathrm{NO}_{2}$ molecules, with the formation of $\{\mathrm{Cu}(\mathrm{I}) \cdots \mathrm{NO}\}$ and $\left\{\mathrm{Cu} \cdots \mathrm{NO}_{2}\right\}$ adducts promoting the conversion of $\mathrm{NO}_{2}$ to $\mathrm{N}_{2}$. This study will inspire the further design and study of new efficient single-atom catalysts for $\mathrm{NO}_{2}$ abatement via detailed unravelling of their role in catalysis.

\section{INTRODUCTION}

Emerging single-atom catalysts show superior selectivity and activity in a variety of catalytic systems due to their unique electronic properties, low-coordination (or unsaturated) metal sites, and high atom efficiency. ${ }^{1-4}$ Metal-organic framework (MOF) materials are a class of crystalline porous materials that are ideal platforms for the fabrication of single-atom catalysts due to their uniform and well-defined structure, ultrahigh porosity, and designable functionality and pore sizes. ${ }^{5-8}$ Functional groups, such as hydroxyl bridges, and intrinsic defect sites in MOFs can enable the immobilization of atomically dispersed metal sites on the pore interior.

MOF-based single-atom catalysts have shown great promise in a number of catalytic reactions, yet the precise identification of these single-atom metal sites and their roles in catalysis remain elusive. $^{9-15}$ As a result, there is a strong motivation to develop and apply cutting-edge experimental techniques to the investigation of local structures of the single metal sites, as well as the elucidation of their roles in catalytic process, thus unravelling the catalytic pathway and mechanism. Recently, a
MOF-based single-atom catalyst, $\mathrm{Cu} / \mathrm{UiO}-66$, has been prepared by anchoring single-atom $\mathrm{Cu}$ sites to the defect sites of $\mathrm{UiO}-66$ and used for catalytic $\mathrm{CO}$ oxidation and removal. ${ }^{16}$ Herein, we conclusively identify the location of the $\mathrm{Cu}$ sites in $\mathrm{Cu} / \mathrm{UiO}-66$, as well as their role in the catalytic reduction of $\mathrm{NO}_{2}$ to $\mathrm{N}_{2}$, an important process for $\mathrm{NO}_{x}$ abatement. The local structure of structural defects and atomically dispersed $\mathrm{Cu}$ sites within the framework and their role in promoting the activation of substrates are elucidated by in situ electron paramagnetic resonance (EPR) spectroscopy, neutron powder diffraction (NPD), inelastic neutron scattering (INS), solid-state nuclear magnetic resonance (NMR) spec-

Received: March 21, 2021

Published: July 19, 2021 


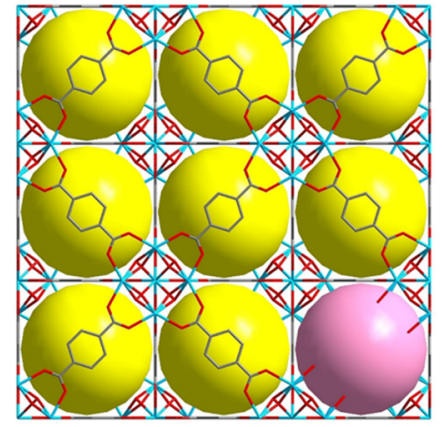

b

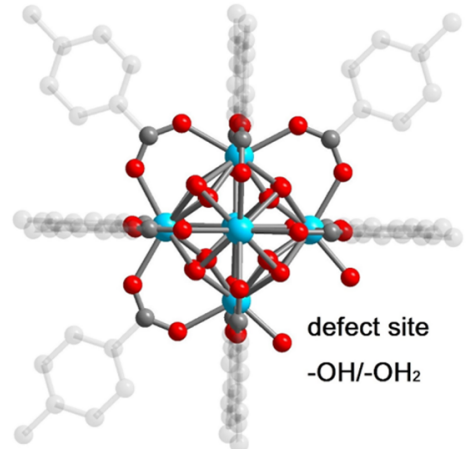

C

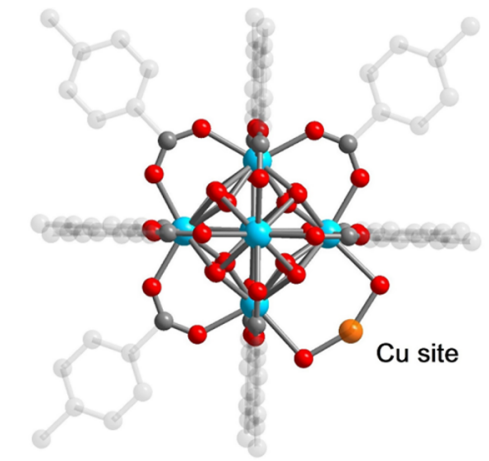

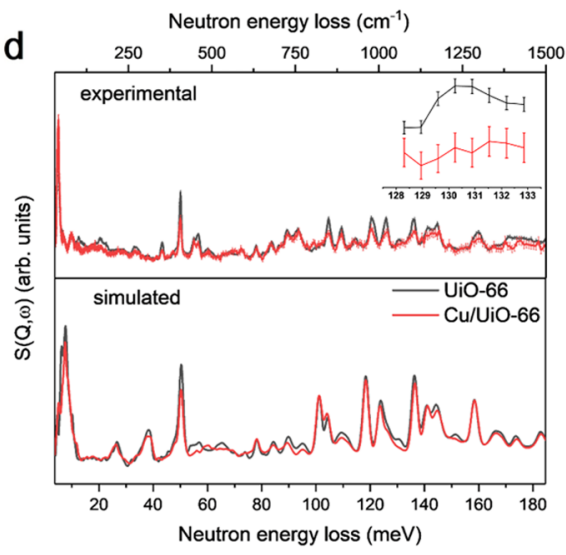

e

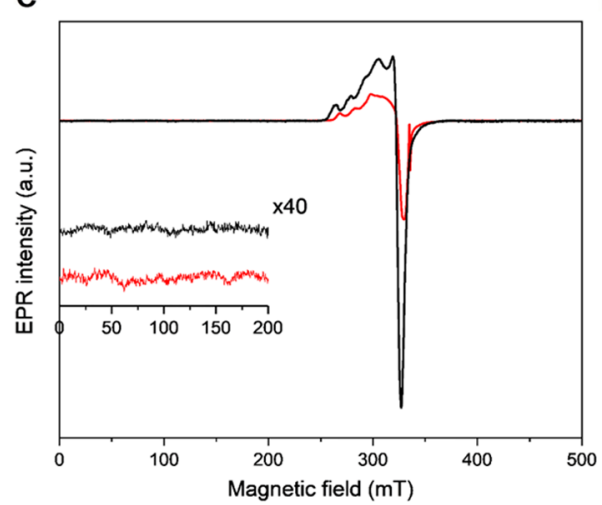

f

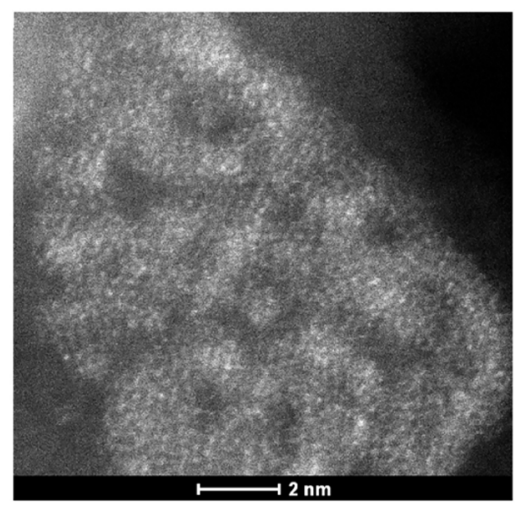

Figure 1. (a) Crystal structure of UiO-66 with a defect site. Yellow and pink spheres represent the cages without and with defect sites, respectively. (b) View of the $\left\{\mathrm{Zr}_{6}\right\}$ cluster in $\mathrm{UiO}-66$ with a defect site and (c) $\mathrm{Cu} / \mathrm{UiO}-66$ with a single-atom $\mathrm{Cu}$ site coordinated to $-\mathrm{OH} /-\mathrm{OH}_{2}$ defect sites. These structures were derived from Rietveld refinements of the NPD data at $7 \mathrm{~K}$ (C, gray; $\mathrm{O}$, red; $\mathrm{Zr}$, blue; $\mathrm{Cu}$, orange; $\mathrm{H}$ atoms are omitted for clarity). The bond distance of $\mathrm{Cu}-\mathrm{O}$ is $1.88(3) \AA$, and the bond angle of $\mathrm{O}-\mathrm{Cu}-\mathrm{O}$ is $152.2(1)^{\circ}$. (d) Comparison of the experimental and DFT calculated INS spectra of UiO-66 and $\mathrm{Cu} / \mathrm{UiO}-66$ (inset: magnification of the experimental INS features at around $130 \mathrm{meV}$ ). (e) X-band (9.4 $\mathrm{GHz}$ ) EPR spectra of $\mathrm{Cu} / \mathrm{UiO}-66$ before (black) and after $\mathrm{H}_{2}$ reduction (red), at $6.4 \mathrm{~K}$ (inset: expansion of low-field region confirming the absence of characteristic signals for binuclear or aggregated $\mathrm{Cu}$ species with $S \geq 1$ ). (f) HAADF-STEM image of $\mathrm{Cu} / \mathrm{UiO}-66$ after $\mathrm{H}_{2}$ reduction.

troscopy, diffuse reflectance infrared Fourier transform spectroscopy (DRIFTS), high-angle annular dark-field scanning transmission electron microscopy (HAADF-STEM), and density functional theory (DFT) calculations. In addition to $\mathrm{Cu} / \mathrm{UiO}-66$, the catalytic performance of the $-\mathrm{NH}_{2}$ functionalized analogue of $\mathrm{UiO}-66\left(\mathrm{UiO}-66-\mathrm{NH}_{2}\right)$ has also been studied to gain insight into the potential activity of $-\mathrm{NH}_{2}$ groups in the reduction of $\mathrm{NO}_{2}$. Of all the catalysts studied herein, $\mathrm{Cu} / \mathrm{UiO}-66$ exhibits superior catalytic performance for the reduction of $\mathrm{NO}_{2}$ to $\mathrm{N}_{2}$ at room temperature without using any reducing agent under the activation of nonthermal plasma (NTP). Cu/UiO-66 shows a superior catalytic stability of $>50$ $\mathrm{h}$ in a continuous flow reaction, affording a $\mathrm{N}_{2}$ selectivity of $88 \%$ at a $97 \%$ conversion of $\mathrm{NO}_{2}$ with an unprecedented turnover frequency (TOF) of $6.1 \mathrm{~h}^{-1}$.

\section{RESULTS AND DISCUSSION}

Synthesis and Characterization of Catalysts. UiO-66 was synthesized according to a reported method (Section S1.1). ${ }^{16} \mathrm{UiO}-66-\mathrm{NH}_{2}$ was prepared using the amine-functionalized ligand (2-aminoterephthalic acid) following the same procedure used for synthesizing UiO-66 (Section S1.1). Powder X-ray diffraction (PXRD) patterns (Figure S1), $\mathrm{N}_{2}$ adsorption isotherms (Figure S2), scanning electron microscopy (SEM, Figure S3) images, and thermal gravimetric analysis (TGA, Figure S4) confirmed the successful prepara- tion of $\mathrm{UiO}-66$ and $\mathrm{UiO}-66-\mathrm{NH}_{2}$. The presence of structural defects (missing ligand) in desolvated UiO-66 was confirmed by NPD (Figure 1a,b), which revealed approximately one missing ligand per $\left\{\mathrm{Zr}_{6}\right\}$ cluster, giving a formula of $\left[\mathrm{Zr}_{6} \mathrm{O}_{4}(\mathrm{OH})_{4}(\mathrm{BDC})_{5.35}(\mathrm{OH})_{1.30}\left(\mathrm{OH}_{2}\right)_{1.30}\right]\left(\mathrm{H}_{2} \mathrm{BDC}\right.$ ligand $=$ benzene-1,4-dicarboxylic acid), in good agreement with previous reports. $^{16-18}$

$\mathrm{Cu} / \mathrm{UiO}-66$ was prepared through the attachment of $\mathrm{Cu}(\mathrm{II})$ ions to the defect sites of $\mathrm{UiO}-66$, followed by reduction by $5 \%$ $\mathrm{H}_{2}$ in $\mathrm{Ar}$ at $250{ }^{\circ} \mathrm{C}$ for $2 \mathrm{~h}^{16}$ The PXRD pattern (Figure S1), $\mathrm{N}_{2}$ adsorption isotherms (Figure S2), and SEM images (Figure $\mathrm{S} 3$ ) of $\mathrm{Cu} / \mathrm{UiO}-66$ confirm the retention of crystallinity, porosity, and crystal morphology upon the attachment of $\mathrm{Cu}$ to $\mathrm{UiO}-66$. Elemental analysis suggested a ratio of $\mathrm{Cu} /\left\{\mathrm{Zr}_{6}\right\}$ of $\sim 1.0$, i.e., all defect sites have been filled by $\mathrm{Cu}$ sites.

Studies of the Atomically Dispersed Cu Sites. The location of $\mathrm{Cu}$ sites within $\mathrm{Cu} / \mathrm{UiO}-66$ has been determined by the Rietveld refinement of NPD data collected at $7 \mathrm{~K}$ (Figure 1c). $\mathrm{Cu}$ is coordinated to the $-\mathrm{OH} /-\mathrm{OH}_{2}$ defect sites of $\mathrm{UiO}-66$ with the ratio of $\mathrm{Cu} /\left\{\mathrm{Zr}_{6}\right\}$ cluster being $\sim 1.0$. The $\mathrm{Cu}-\mathrm{O}$ distance $[1.88(3) \AA]$ is in excellent agreement with that (1.89-1.95 $\AA$ ) obtained from DFT calculations. ${ }^{16}$ The binding of $\mathrm{Cu}$ to the $-\mathrm{OH} /-\mathrm{OH}_{2}$ defect sites was confirmed further by a combination of inelastic neutron scattering (INS) and DFT calculations (Figure 1d). Upon the binding of $\mathrm{Cu}$, the INS features at 57 and $130 \mathrm{meV}$, assigned to $\mathrm{O}-\mathrm{H}$ bending modes, show notable reductions in intensity, confirming the 

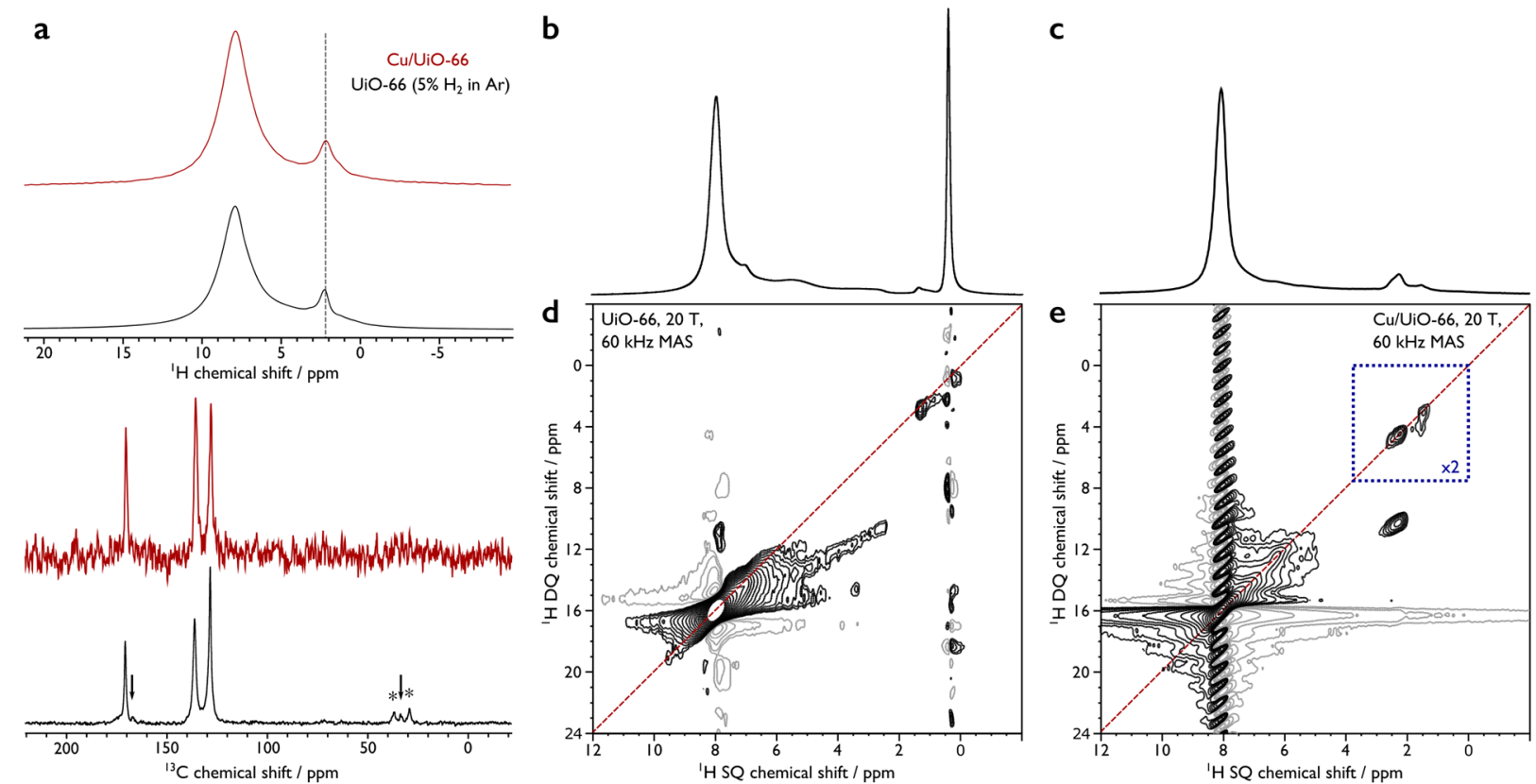

Figure 2. (a) ${ }^{1} \mathrm{H}$ DEPTH (top) and $\left\{{ }^{1} \mathrm{H}-\right\}^{13} \mathrm{C} \mathrm{CP}$ (bottom) MAS NMR spectra of $\mathrm{H}_{2}$-reduced UiO-66 (black) and Cu/UiO-66 (red). The spectra were recorded at $9.4 \mathrm{~T}$ using a MAS frequency of $10 \mathrm{kHz}$. The arrows and asterisks denote trace adsorbed DMF molecules and the spinning side bands, respectively. The dashed vertical gray line highlights the defect sites. ${ }^{1} \mathrm{H}$ DEPTH MAS NMR spectra of (b) UiO-66 and (c) Cu/UiO-66. 2D ${ }^{1} \mathrm{H}$ MAS NMR DQ-SQ homonuclear dipolar correlation spectra of (d) UiO-66 and (e) Cu/UiO-66, recorded using the $\mathrm{S}_{3}$ recoupling sequence; black and gray lines represent positive and negative contours, respectively, and the dashed red line highlights the DQ diagonal. The blue square in (e) represents an area where the minimum displayed contour level has been decreased by a factor of 2 (equivalent to doubled magnification). The spectra were recorded at $20 \mathrm{~T}$ using a MAS frequency of $60 \mathrm{kHz}$.

coordination of $\mathrm{Cu}$ to these defect sites, and this was validated by DFT simulations of the INS spectra. The simulations tend to slightly underestimate the magnitude of the reduction in intensities of the small features at $100-160 \mathrm{meV}$, likely due to the overall complexity of the system. This represents the first study of the location of $\mathrm{Cu}$ sites within $\mathrm{Cu} / \mathrm{UiO}-66$ by diffraction techniques.

Following the determination of the location of the $\mathrm{Cu}$ sites, it was established that these were primarily atomically dispersed. Thus, the continuous-wave EPR spectra of $\mathrm{Cu}$ / UiO-66 before and after reduction under $\mathrm{H}_{2}$ both show the characteristics of monomeric $\mathrm{Cu}(\mathrm{II})$ sites (Figure 1e). ${ }^{19}$ No binuclear $(S=1)$ or aggregated (long-range magnetically coupled) $\mathrm{Cu}(\mathrm{II})$ species was observed by the X-band EPR spectra collected at low and room temperatures (Figure 1e and Figure S7), ${ }^{20}$ consistent with the presence of atomically dispersed $\mathrm{Cu}(\mathrm{II})$ sites in the framework. The EPR spectra of reduced $\mathrm{Cu} / \mathrm{UiO}-66$ show that the majority of the $\mathrm{Cu}$ (II) sites are reduced to diamagnetic $\mathrm{Cu}(\mathrm{I})$ (Figure $\mathrm{S} 8$ ), which is consistent with X-ray photoelectron spectroscopic (XPS) analysis (Figure S17). The high-angle annular dark-field scanning transmission electron microscopy (HAADF-STEM) of $\mathrm{Cu} / \mathrm{UiO}-66$ shows many bright dots, representing $\mathrm{Cu}$ and $\mathrm{Zr}$ sites (Figure 1f and Figure S9a). ${ }^{21}$ Although it is challenging to distinguish between $\mathrm{Cu}$ and $\mathrm{Zr}$ centers, ${ }^{22}$ the HAADFSTEM image confirms the absence of $\mathrm{Cu} / \mathrm{CuO}_{x}$ nanoparticles. Energy dispersive $\mathrm{X}$-ray spectroscopy (EDX) mapping also shows a uniform distribution of the $\mathrm{Cu}$ sites (Figure S9c,d). This was further validated by the ultraviolet-visible (UV-vis) absorption spectrum of $\mathrm{Cu} / \mathrm{UiO}-66$, where the characteristic absorption peak of $\mathrm{Cu}$ nanoparticles [surface plasmon resonance (SPR) band] in the region of $550-600 \mathrm{~nm}^{23}$ was not observed (Figure S10).
Analysis of Structural Defects and the Environment of $\mathrm{Cu}$ by Solid-State NMR. To gain further insights into the local environment of defects and $\mathrm{Cu}$ sites, solid-state NMR spectroscopy was employed as this has proven extremely valuable in the study of UiO-66 materials. ${ }^{24,25}$ Here, a quantitative ${ }^{1} \mathrm{H}$ magic angle spinning (MAS) NMR spectrum of reduced $\mathrm{UiO}-66$, obtained following the same treatment as $\mathrm{Cu} / \mathrm{UiO}-66$ (i.e., heating in $5 \% \mathrm{H}_{2}$ in $\mathrm{Ar}$ at $250{ }^{\circ} \mathrm{C}$ for $2 \mathrm{~h}$ ), shows that this treatment removes the $\mathrm{H}$ center from the $\mu^{3}-$ $\mathrm{OH}$ species of the $\left\{\mathrm{Zr}_{6}\right\}$ cluster (Figure $2 \mathrm{a}$, top), which was previously observed by variable-temperature FTIR studies. ${ }^{26}$ ${ }^{1} \mathrm{H}$ NMR signals from low-shifted species $\left(\delta\left\{{ }^{1} \mathrm{H}\right\}<2.5 \mathrm{ppm}\right)$ account for $\sim 1 / 10$ th of the integral intensity compared to ${ }^{1} \mathrm{H}$ from the ligands $\left(\delta\left\{{ }^{1} \mathrm{H}\right\} \sim 8 \mathrm{ppm}\right.$ ) (Figure S11 and Table S3), whereas this intensity is expected to be 4 times larger for fully hydroxylated UiO-66. Therefore, these low-shifted species were assigned as $-\mathrm{OH} /-\mathrm{OH}_{2}$ centers at defect sites. The ${ }^{1} \mathrm{H}$ MAS NMR spectrum of $\mathrm{Cu} / \mathrm{UiO}-66$ (Figure 2a, top) is similar to that of reduced UiO-66, indicating that the majority of $\mathrm{Cu}(\mathrm{II})$ sites were reduced to $\mathrm{Cu}(\mathrm{I})$; a close proximity to paramagnetic $\mathrm{Cu}(\mathrm{II})$ ions would cause a substantial broadening and/or shifts of the NMR signals, ${ }^{27}$ and this was not observed. The similarity between the ${ }^{13} \mathrm{C}$ MAS NMR spectra of reduced $\mathrm{UiO}-66$ and $\mathrm{Cu} / \mathrm{UiO}-66$ (Figure 2a, bottom) demonstrates that the incorporation of $\mathrm{Cu}$ sites does not perturb the local ligand structure.

High-field $(20 \mathrm{~T}){ }^{1} \mathrm{H}$ NMR spectroscopy with ultrafast MAS was also employed as this provides superior resolution. The two-dimensional (2D) double-quantum single-quantum (DQSQ) ${ }^{1} \mathrm{H}$ homonuclear dipolar correlation NMR spectrum (Figure $2 \mathrm{~d}$ ) for pristine $\mathrm{UiO}-66$ shows the $\mu^{3}-\mathrm{OH}$ species at $\delta$ $\left\{{ }^{1} \mathrm{H}\right\} \sim 0.4 \mathrm{ppm}$ (Figure $2 \mathrm{~b}$ and Figure S11). The remaining low-shifted protons at $\delta\left\{{ }^{1} \mathrm{H}\right\}<2.5 \mathrm{ppm}$ display both diagonal 
a $\quad \mathrm{NO}_{2}$ Conversion $\quad \mathrm{N}_{2}$ Selectivity $\quad$ NO Selectivity $\quad \mathrm{N}_{2} \mathrm{O}$ Selectivity

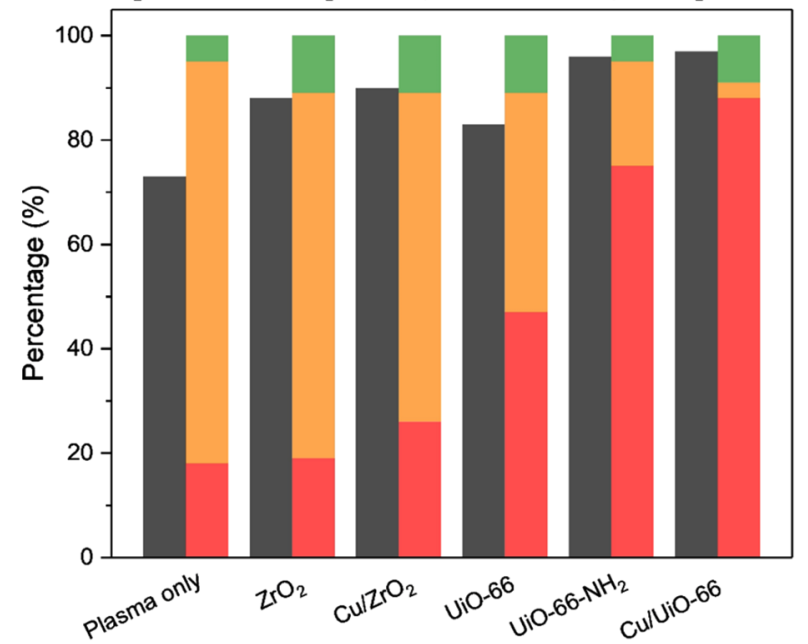

b

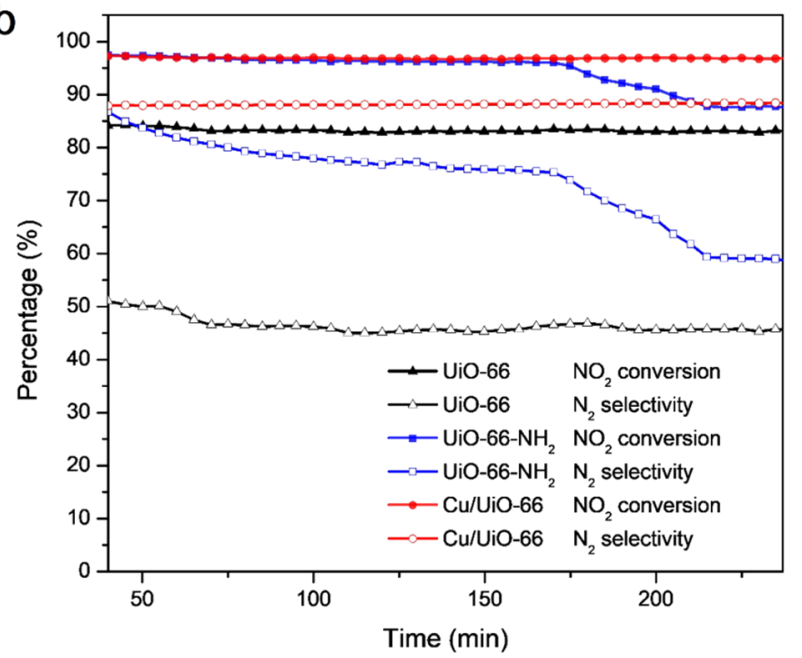

Figure 3. (a) Catalytic performance $\left(\mathrm{NO}_{2}\right.$ conversion and product selectivities) over different catalysts under steady-state NTP conditions. (b) Time-on-stream plots of $\mathrm{NO}_{2}$ conversion and $\mathrm{N}_{2}$ selectivity over MOF-based catalysts (UiO-66, $\mathrm{UiO}-66-\mathrm{NH}_{2}$, and $\mathrm{Cu}$ / UiO-66) under NTP conditions $\left(0.4 \mathrm{~kJ} \mathrm{~L}^{-1}, 10 \mathrm{kHz}, 500 \mathrm{ppm}\right.$ of $\mathrm{NO}_{2}$ diluted in $\mathrm{He}, 25^{\circ} \mathrm{C}$, and atmospheric pressure).

autocorrelation peaks (between equivalent proton sites at $\delta_{\mathrm{DQ}}$ $\left\{{ }^{1} \mathrm{H}\right\} \sim 2.7 \mathrm{ppm}$ ) and off-diagonal correlation peaks (between inequivalent proton sites at $\delta_{\mathrm{DQ}}\left\{{ }^{1} \mathrm{H}\right\} \sim 2.4 \mathrm{ppm}$ ). Accordingly, these proton environments can be assigned to defect sites (Figure $1 \mathrm{~b}$ ), where $\mu^{1}-\mathrm{OH}_{2}$ species $\left(\delta_{\mathrm{SQ}}\left\{{ }^{1} \mathrm{H}\right\} \sim 1.3 \mathrm{ppm}\right.$ ) will give an autocorrelation peak and nearby $\mu^{1}-\mathrm{OH}$ species
$\left(\delta_{\mathrm{SQ}}\left\{{ }^{1} \mathrm{H}\right\} \sim 1.1 \mathrm{ppm}\right)$ will be correlated to these (offdiagonal).

The high-resolution ${ }^{1} \mathrm{H}$ MAS NMR spectrum of $\mathrm{Cu} / \mathrm{UiO}-66$ confirms the absence of $\mu^{3}-\mathrm{OH}$ species for this sample (Figure $2 c)$. It is also evident that there are at least three distinct defect $-\mathrm{OH} /-\mathrm{OH}_{2}$ environments at $\delta\left\{{ }^{1} \mathrm{H}\right\} \sim 2.4,2.2$, and $1.5 \mathrm{ppm}$. The 2D DQ-SQ ${ }^{1} \mathrm{H}$ homonuclear dipolar correlation NMR spectrum of $\mathrm{Cu} / \mathrm{UiO}-66$ (Figure 2e) displays clear and intense autocorrelation peaks for two of the defect sites (at $\delta_{\mathrm{SQ}}\left\{{ }^{1} \mathrm{H}\right\} \sim$ 2.4 and $2.2 \mathrm{ppm}$ ), indicating that they arise from $\mathrm{OH}_{2}$ environments. Furthermore, these species also give a strong correlation with protons from the linker (at $\delta_{\mathrm{DQ}}\left\{{ }^{1} \mathrm{H}\right\} \sim 10.3$ $\mathrm{ppm}$ ), suggesting that they are somewhat removed from the defect site. The remaining defect proton environments are thus likely to be $-\mathrm{OH}$ sites (at $\delta_{\mathrm{SQ}}\left\{{ }^{1} \mathrm{H}\right\} \sim 1.5 \mathrm{ppm}$ ), and crosscorrelations with $\mathrm{OH}_{2}$ environments suggest that these sites are all in close proximity and remain protonated upon the attachment of $\mathrm{Cu}$ sites. A quantitative comparison (Figure S11 and Table S3) between the defect sites of UiO-66 and $\mathrm{Cu} /$ UiO-66 suggests that displacement of adsorbed water and/or dehydroxylation of the $\left\{\mathrm{Zr}_{6}\right\}$ clusters during $\mathrm{Cu}$ attachment and subsequent $\mathrm{H}_{2}$-reduction leads to a $\sim 4$-fold increase in the relative amount of protons at the defect sites $\left(\delta\left\{{ }^{1} \mathrm{H}\right\}<2.5\right.$ $\mathrm{ppm})$. The autocorrelation peak of the lowest-shifted ${ }^{1} \mathrm{H}$ species of $\mathrm{Cu} / \mathrm{UiO}-66\left(\right.$ at $\left.\delta_{\mathrm{SQ}}\left\{{ }^{1} \mathrm{H}\right\} \sim 1.5 \mathrm{ppm}\right)$ and its crosscorrelation to $\mathrm{OH}_{2}$ environments indicates that $\mathrm{Cu}$ is coordinated at defect sites as $\left\{\mathrm{Zr}-\mathrm{O}(\mathrm{H})-\mathrm{Cu}\left(\mathrm{OH}_{2}\right)-\right.$ $\mathrm{O}(\mathrm{H})-\mathrm{Zr}$. Quantitatively, this coordination mode appears approximately once every two $\left\{\mathrm{Zr}_{6}\right\}$ clusters. The other coordination modes of $\mathrm{Cu}$ sites are $\left\{\mathrm{Zr}-\mathrm{O}-\mathrm{Cu}\left(\mathrm{OH}_{2}\right)-\mathrm{O}-\right.$ $\mathrm{Zr}\}$ and $\{\mathrm{Zr}-\mathrm{O}-\mathrm{Cu}-\mathrm{O}-\mathrm{Zr}\}$. These coordination modes were confirmed by ${ }^{1} \mathrm{H}$ hyperfine sublevel correlation (HYSCORE) EPR spectra (Figure S12 and Table S4), which reveal a coordinated $\mathrm{H}_{2} \mathrm{O}$ molecule in the plane perpendicular to the $z$ axis of the electronic $g$ matrix (the latter being perpendicular to the coordination plane) with a $\mathrm{Cu} \cdots \mathrm{H}$ distance of $\sim 2.3 \AA$.

Studies of Catalytic Performance. To investigate the catalytic performance of $\mathrm{UiO}-66, \mathrm{UiO}-66-\mathrm{NH}_{2}$, and $\mathrm{Cu} / \mathrm{UiO}-$ 66 for NTP-assisted decomposition of $\mathrm{NO}_{2}$, a simulated gas flow containing $500 \mathrm{ppm}$ of $\mathrm{NO}_{2}$ diluted in helium at a total flow rate of $100 \mathrm{~mL} \mathrm{~min}^{-1}$ was used as the feed gas for a proofof-concept study. Without a catalyst, the gas phase NTP alone exhibited a conversion of $\mathrm{NO}_{2}\left(\mathrm{C}_{\mathrm{NO}_{2}}\right)$ of $73 \%$ with a low selectivity of $\mathrm{N}_{2}\left(S_{\mathrm{N}_{2}}\right)$ of $18 \%$, with the majority of $\mathrm{NO}_{2}$ being converted to NO, which is another major air pollutant that can be oxidized to $\mathrm{NO}_{2}$ in air (Figure 3, Table 1, Entry 1). All three MOF catalysts can improve the $C_{\mathrm{NO}_{2}}$ and $S_{\mathrm{N}_{2}}$ (Figure 3, Table 1, Entries 2-5). UiO-66 showed a steady $C_{\mathrm{NO}_{2}}$ of $83 \%$ with a $S_{\mathrm{N}_{2}}$ of $47 \%$ over $240 \mathrm{~min}$ (Figure $3 \mathrm{~b}$ ).

Table 1. Summary of the $\mathrm{NO}_{2}$ Conversion and Product Selectivities over Different Catalysts ${ }^{a}$

\begin{tabular}{lccc}
\multicolumn{1}{c}{ catalyst } & $\mathrm{NO}_{2}$ conversion (\%) & $\mathrm{N}_{2}$ selectivity (\%) & NO selectivity (\%) \\
empty tube & 73 & 18 & 77 \\
UiO-66 & 83 & 47 & 42 \\
$\mathrm{UiO}-66\left(\mathrm{H}_{2}\right.$-reduced) & 85 & 50 & 11 \\
$\mathrm{UiO}-66-\mathrm{NH}_{2}$ & 96 & 75 & 40 \\
$\mathrm{Cu} / \mathrm{UiO}-66$ & 97 & 88 & 20 \\
$\mathrm{ZrO} 2$ & 88 & 19 & 3 \\
$\mathrm{Cu} / \mathrm{ZrO}_{2}$ & 90 & 26 & 9
\end{tabular}

${ }^{a}$ Reaction conditions: $0.4 \mathrm{~kJ} \mathrm{~L}-1,10 \mathrm{kHz}, 500 \mathrm{ppm}$ of $\mathrm{NO}_{2}$ diluted in $\mathrm{He}, 25{ }^{\circ} \mathrm{C}$, and atmospheric pressure. 

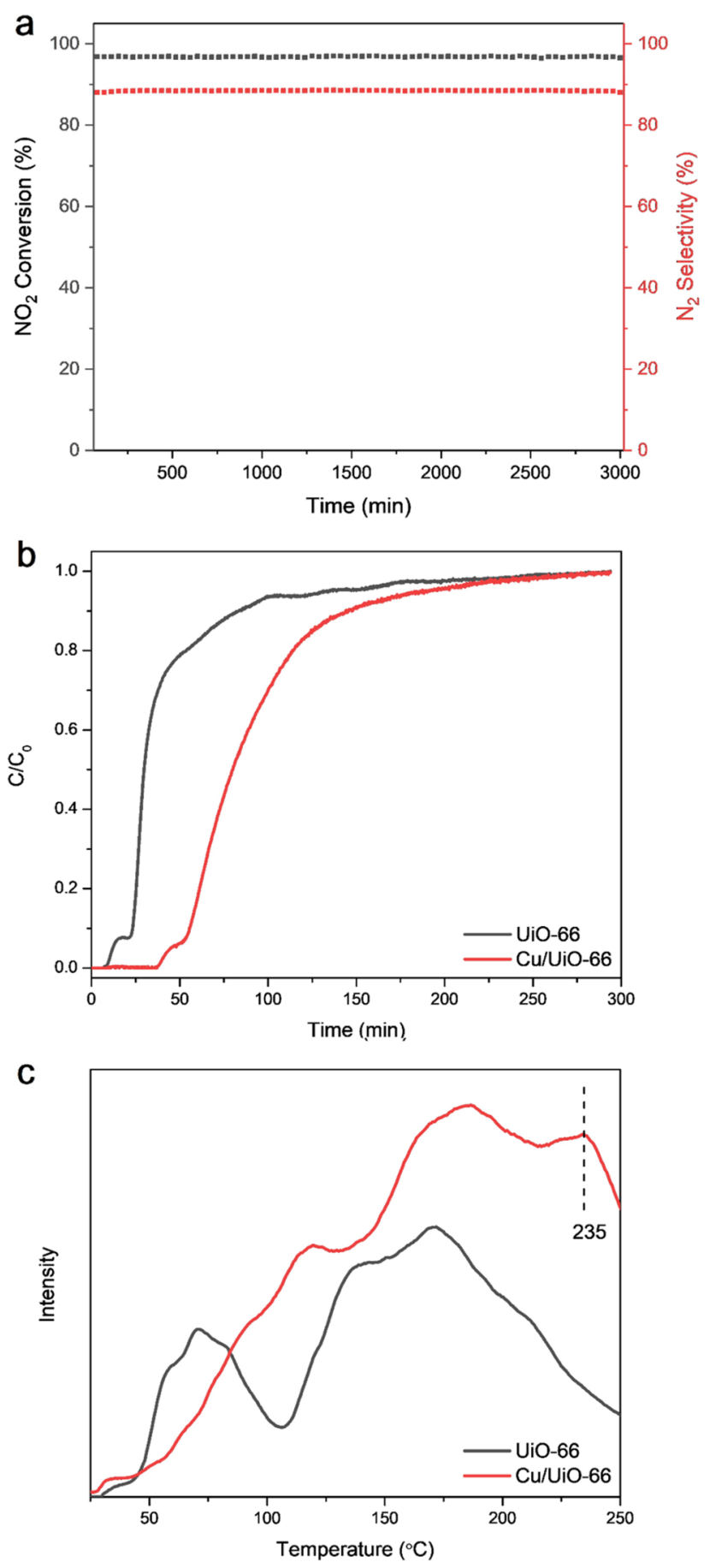

Figure 4. (a) Time-on-stream test of $\mathrm{Cu} / \mathrm{UiO}-66$ under NTP conditions. The catalytic efficiency remained constant for $50 \mathrm{~h}$ of reaction under continuous flow. (b) Dynamic breakthrough experiments of UiO-66 and $\mathrm{Cu} / \mathrm{UiO}-66$ using the same $\mathrm{NO}_{2} / \mathrm{He}$ gas feed at $25{ }^{\circ} \mathrm{C}$. (c) $\mathrm{NO}_{2}$-TPD plots of $\mathrm{UiO}-66$ and $\mathrm{Cu} / \mathrm{UiO}-66$.

The $\mathrm{NH}_{2}$-functionalized $\mathrm{UiO}-66-\mathrm{NH}_{2}$ showed improvements to the catalytic activity observed for UiO-66, with the $C_{\mathrm{NO}_{2}}$ and $S_{\mathrm{N}_{2}}$ reaching $96 \%$ and $75 \%$, respectively. However, a notable deactivation of UiO-66- $\mathrm{NH}_{2}$ occurred after $170 \mathrm{~min}$, where the $C_{\mathrm{NO}_{2}}$ and $S_{\mathrm{N}_{2}}$ dropped gradually to $88 \%$ and $59 \%$, respectively, after $240 \mathrm{~min}$ (Figure $3 \mathrm{~b}$ ). The operando DRIFTS spectrum of $\mathrm{UiO}-66-\mathrm{NH}_{2}$ exposed to $\mathrm{NO}_{2}$ under plasma activation (Figure S20) shows a new band at $2280 \mathrm{~cm}^{-1}$ assigned to a diazonium salt ${ }^{28}$ and a decrease in intensity of the bands at 3514 and $3398 \mathrm{~cm}^{-1}$ assigned to asymmetric and symmetric $\mathrm{N}-\mathrm{H}$ stretches. These observations suggest that the $-\mathrm{NH}_{2}$ group acts as a sacrificial agent in this reaction, with the deactivation of the catalyst being driven by the formation and dissociation of the diazonium ions upon irreversible reaction between $\mathrm{NO}_{2}$ and the $-\mathrm{NH}_{2}$ groups of $\mathrm{UiO}-66-\mathrm{NH}_{2}$. Despite the $-\mathrm{NH}_{2}$ sites being consumed during the reaction, the overall structure of the framework in $\mathrm{UiO}-66-\mathrm{NH}_{2}$ was retained, as confirmed by PXRD (Figure S14).

Of the three catalysts, $\mathrm{Cu} / \mathrm{UiO}-66$ exhibits the highest catalytic efficiency, with the $C_{\mathrm{NO}_{2}}$ and $S_{\mathrm{N}_{2}}$ reaching $97 \%$ and $88 \%$, respectively (Figure 3 and Table 1, Entry 5). Time-onstream $(\mathrm{ToS})$ tests further demonstrated the excellent catalytic stability of Cu/UiO-66 with high values for $C_{\mathrm{NO}_{2}}$ and $S_{\mathrm{N}_{2}}$ retained for over $50 \mathrm{~h}$ (Figure $4 \mathrm{a}$ ). Importantly, $\mathrm{Cu} / \mathrm{UiO}-66$ exhibited a superior TOF of $6.1 \mathrm{~h}^{-1}$ compared with state-ofthe-art Cu-based SCR catalysts, including those using $\mathrm{NH}_{3}$ as reductant and operating at elevated temperatures (Table 2). For example, a Cu-exchanged SSZ-13 zeolite ${ }^{29}$ shows a TOF value of $1.9-2.2 \mathrm{~h}^{-1}$ at $250-550{ }^{\circ} \mathrm{C}$ and $\mathrm{Cu}-\mathrm{MOF}-74^{30}$ demonstrates a TOF of $0.28 \mathrm{~h}^{-1}$ at $230{ }^{\circ} \mathrm{C}$. Significantly, the excellent catalytic activity of $\mathrm{Cu} / \mathrm{UiO}-66$ was achieved without the use of $\mathrm{NH}_{3}$ or heating. In contrast, $\mathrm{Cu} / \mathrm{ZrO}_{2}$, prepared through a similar method as for $\mathrm{Cu} / \mathrm{UiO}-66$ (Section $\mathrm{S} 1.1$ ), showed a much lower catalytic efficiency, with values of $90 \%$ and $26 \%$ for $\mathrm{C}_{\mathrm{NO}_{2}}$ and $S_{\mathrm{N}_{2}}$, respectively( Figure 3a and Table 1, Entry 7), indicating that the nature of atomically dispersed $\mathrm{Cu}$ sites within $\mathrm{Cu} / \mathrm{UiO}-66$ plays a crucial role in its observed activity. Although NTP-activated $\operatorname{deNO}_{x}$ systems have been reported, ${ }^{31-33}$ they generally suffer from poor catalytic efficiency, low TOF, and/or stability.

To explore possible sample degradation, the used $\mathrm{Cu} / \mathrm{UiO}-$ 66 catalyst was characterized by EPR, XPS, PXRD, DRIFTS, and $\mathrm{N}_{2}$ adsorption isotherms. The X-band EPR spectrum of the used catalyst confirms (Figure S16) the retention of atomically dispersed $\mathrm{Cu}$ sites, with no evidence of aggregated species. The EPR spectrum also shows a small increase in the intensity of $\mathrm{Cu}(\mathrm{II})$ signal after reaction (Figure S8). XPS spectra indicate that the ratio of $\mathrm{Cu}(\mathrm{II}) / \mathrm{Cu}(\mathrm{I})$ increases after reaction, but with the majority of $\mathrm{Cu}$ sites still remaining as $\mathrm{Cu}(\mathrm{I})$ in the used catalyst (Figure S17). Little difference was observed in the PXRD patterns or DRIFTS spectra of fresh and used catalysts (Figures S15 and S18). $\mathrm{N}_{2}$ adsorption isotherms at $77 \mathrm{~K}$ indicate a small reduction $(\sim 10 \%)$ in the surface area of $\mathrm{Cu} / \mathrm{UiO}-66$ after reaction (Figure S19).

Studies of the Reaction Mechanism. The adsorption of $\mathrm{NO}_{2}$ onto the catalyst is widely considered as the ratedetermining step for the reduction of $\mathrm{NO}_{2},{ }^{34}$ and dynamic breakthrough experiments were therefore carried out with $\mathrm{UiO}-66$ and $\mathrm{Cu} / \mathrm{UiO}-66$ at $25{ }^{\circ} \mathrm{C}$ (Figure $4 \mathrm{~b}$ ). Notably, the dynamic adsorption capacity of $\mathrm{NO}_{2}$ in UiO-66 increases from 2.02 to $3.96 \mathrm{mmol} \mathrm{g}^{-1}$ on incorporation of $\mathrm{Cu}$ sites, and the temperature-programmed desorption (TPD) profiles of $\mathrm{NO}_{2}$ adsorbed onto $\mathrm{UiO}-66$ and $\mathrm{Cu} / \mathrm{UiO}-66$ show the presence of stronger binding sites for $\mathrm{NO}_{2}$ in the latter with an additional desorption peak at $235{ }^{\circ} \mathrm{C}$ (Figure 4c). Thus, both breakthrough and TPD experiments confirm the stronger adsorption of $\mathrm{NO}_{2}$ in $\mathrm{Cu} / \mathrm{UiO}-66$ than in UiO-66, presumably contributing to the observed superior catalytic performance.

In situ DRIFTS spectroscopy confirmed the adsorption of $\mathrm{NO}_{2}$, resulting in several new bands at $\sim 1541,1487,1415$, 


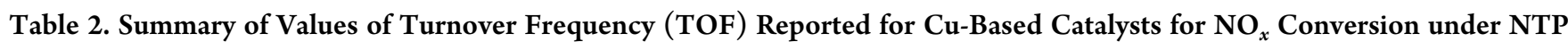
Conditions and Thermal Conditions with Reducing Agents ${ }^{a}$

\begin{tabular}{|c|c|c|c|c|c|c|}
\hline catalyst & temperature $\left({ }^{\circ} \mathrm{C}\right)$ & GHSV $\left(10^{3} h^{-1}\right)$ & $\mathrm{NO}_{x}$ concentration $(\mathrm{ppm})$ & $\mathrm{NO}_{x}$ conversion $(\%)$ & TOF $\left(h^{-1}\right)$ & $\operatorname{ToS}(\mathrm{h})$ \\
\hline Cu/UiO-66@NTP [this work] & 25 & 150 & 500 & 97.0 & 6.1 & 50 \\
\hline HKUST-1@NTP ${ }^{31}$ & 25 & 75 & 500 & 97.9 & 0.27 & 0.50 \\
\hline Cu/ZSM-5@NTP-NH ${ }_{3}^{32}$ & 25 & 60 & 500 & 21.0 & 0.62 & \\
\hline $\mathrm{Cu} / \mathrm{ZSM}-5 @ \mathrm{NTP}-\mathrm{NH}_{3}{ }^{32}$ & 180 & 60 & 500 & 60.0 & 1.8 & \\
\hline Cu/MFM-300(Al)@NTP 33 & 25 & 150 & 500 & 96 & 2.9 & 3.8 \\
\hline Cu-SSZ-13@thermal-NH ${ }_{3}{ }^{29}$ & 250 & 30 & 350 & 95.0 & 2.2 & \\
\hline Cu-SSZ-13@thermal-NH ${ }_{3}^{29}$ & 550 & 30 & 350 & 83.0 & 1.9 & \\
\hline Cu-MOF-74@thermal-NH ${ }_{3}^{30}$ & 230 & 50 & 1000 & 97.8 & 0.28 & 24 \\
\hline Cu/SAPO-34@thermal-NH ${ }_{3}^{46}$ & 210 & 36 & 500 & 90.0 & 1.0 & \\
\hline Cu/SAPO-34@thermal-NH3 ${ }^{46}$ & 360 & 36 & 500 & 100 & 1.1 & \\
\hline Cu-ZSM-5@thermal-NH ${ }_{3}{ }^{47}$ & 150 & 100 & 500 & 48.0 & 2.4 & \\
\hline Cu-ZSM-5@thermal- $\mathrm{NH}_{3}{ }^{47}$ & 300 & 100 & 500 & 100 & 4.9 & \\
\hline HKUST-1@thermal-NH ${ }_{3}^{48}$ & 280 & 50 & 1000 & 95.5 & 0.26 & \\
\hline $\mathrm{CuO} @$ thermal- $\mathrm{NH}_{3}{ }^{49}$ & 270 & 50 & 1000 & 97.2 & 0.12 & 25 \\
\hline
\end{tabular}
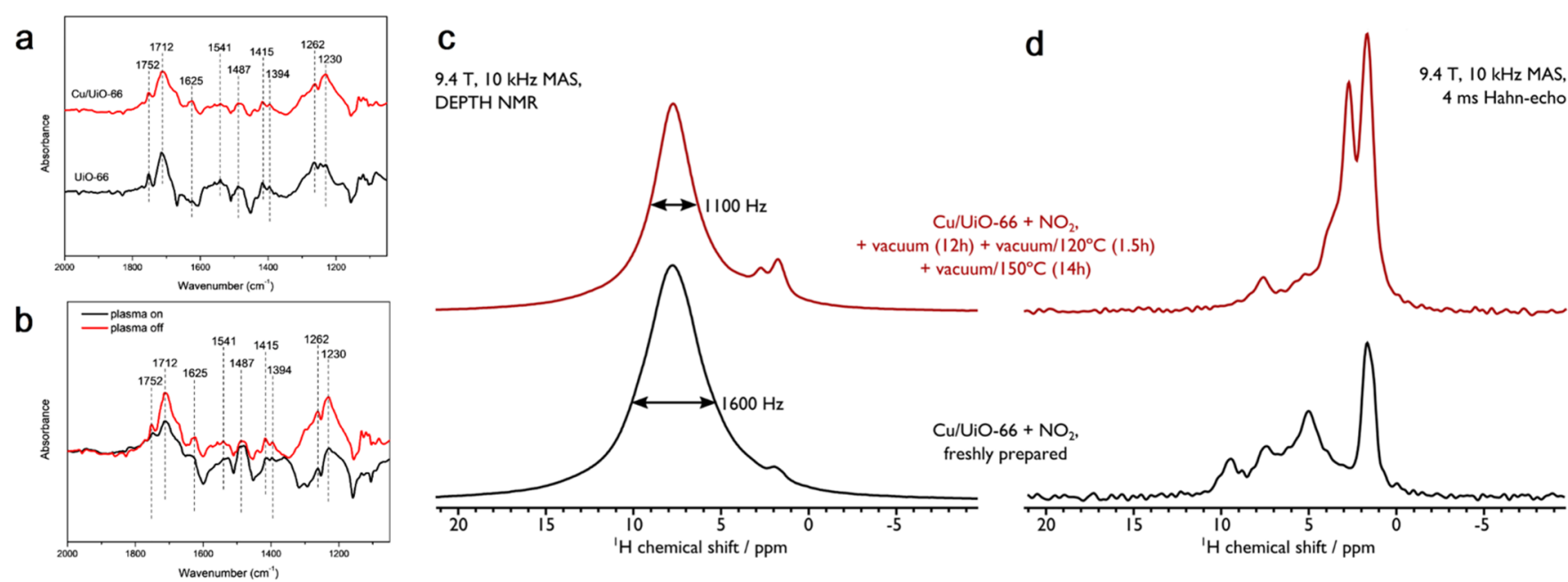

Figure 5. (a) In situ DRIFTS spectra of adsorbed $\mathrm{NO}_{2}$ on $\mathrm{Cu} / \mathrm{UiO}-66$ (red) and UiO-66 (black). (b) Operando DRIFTS spectra over Cu/UiO-66 with plasma on (black) and off (red); $500 \mathrm{ppm}$ of $\mathrm{NO}_{2}$ in He was used as a feed gas. All the DRIFTS spectra were recorded at a resolution of 4 $\mathrm{cm}^{-1}$; the spectra of bare MOF samples were subtracted as the background. (c) ${ }^{1} \mathrm{H}$ DEPTH and (d) ${ }^{1} \mathrm{H}-\mathrm{Hahn}$-echo MAS NMR spectra of Cu/ UiO-66 dosed with $\mathrm{NO}_{2}$ for 15 min (black) and the same sample after $\mathrm{NO}_{2}$ desorption (red). A further desorption study can be found in the Supporting Information.

1394, 1262, and $1230 \mathrm{~cm}^{-1}$ (Figure 5a) assigned to various monodentate, bidentate, and bridging nitro/nitrate species $^{35-37}$ adsorbed on catalyst surfaces with partially overlapping vibrational bands. The band at $1712 \mathrm{~cm}^{-1}$ is associated with adsorbed $\mathrm{NO}$ on the $-\mathrm{OH}$ defect sites in both $\mathrm{UiO}-66$ and $\mathrm{Cu} / \mathrm{UiO}-66$, and the notable broadening and increase of intensity of this band in $\mathrm{Cu} / \mathrm{UiO}-66$ is due to the additional contribution from the formation of $\{\mathrm{Cu}(\mathrm{I}) \cdots \mathrm{NO}\}$ species. $^{38,39}$ The adsorption of $\mathrm{NO}$ onto the $-\mathrm{OH}$ defect sites was further confirmed by the depletion of the $\mathrm{O}-\mathrm{H}$ stretching vibration band at $3675 \mathrm{~cm}^{-1}$ (Figure S21). Interestingly, an additional band was observed at $1625 \mathrm{~cm}^{-1}$ for $\mathrm{NO}_{2}$-loaded $\mathrm{Cu} / \mathrm{UiO}-66$, which could originate from adsorbed $\mathrm{NO}_{2}$ or $\mathrm{NO}$ species on $\mathrm{Cu}$ sites. ${ }^{35,40,41}$ Thus, the formation of $\left\{\mathrm{Cu} \cdots \mathrm{NO}_{2}\right\}$ adducts on $\mathrm{Cu} / \mathrm{UiO}-66$ greatly accelerates the adsorption and reduction of $\mathrm{NO}_{2}$. The EPR spectroscopic studies of $\mathrm{Cu} / \mathrm{UiO}-66$ and $\mathrm{NO}_{2}-$ loaded $\mathrm{Cu} / \mathrm{UiO}-66$ also show differences in both the $g$ - and $\mathrm{Cu}$ hyperfine $A$-tensors (Figure S22), consistent with binding of $\mathrm{NO}_{x}$ at $\mathrm{Cu}$ sites. Operando DRIFTS experiments were carried out as a function of plasma on-off and reaction time (Figure 5b). Apparent reductions of FTIR bands of various adsorbed nitro/nitrate species, $\{\mathrm{Cu}(\mathrm{I}) \cdots \mathrm{NO}\}$, and $\left\{\mathrm{Cu} \cdots \mathrm{NO}_{2}\right\}$ adducts were observed upon the ignition of plasma, indicating the rapid conversion of these intermediates over $\mathrm{Cu} / \mathrm{UiO}-66$. It is worth noting that, in the present system, the activation effects of NTP coupled to the adsorption of $\mathrm{NO}_{2}$ by the catalyst appear to work synergistically.

In situ ${ }^{1} \mathrm{H}$ MAS NMR spectra were recorded for $\mathrm{Cu} / \mathrm{UiO}-66$ upon the adsorption of $\mathrm{NO}_{2}$ to investigate the adsorbates as well as the local structural changes of the catalyst. The adsorption of $\mathrm{NO}_{2}$ has substantial effects (cf. Figures 2a and 5c) with the broadening of the ${ }^{1} \mathrm{H}$ NMR signals from the ligand (at $\delta\left\{{ }^{1} \mathrm{H}\right\} \sim 8 \mathrm{ppm}$ ) and a decrease in the intensity of signals due to the defect sites (at $\delta\left\{{ }^{1} \mathrm{H}\right\}<2.5 \mathrm{ppm}$ ). To investigate the broadening, a ${ }^{1} \mathrm{H}$ Hahn-echo experiment ${ }^{42}$ was employed with a relatively long total echo duration (Figure $5 \mathrm{~d}$ ) as this will remove homogeneously broadened signals [e.g., from ${ }^{1} \mathrm{H}$ centers near $\mathrm{Cu}(\mathrm{II})$ sites or with strong dipolar couplings]. Subsequently, the adsorbed $\mathrm{NO}_{2}$ was removed using vacuum/heating treatment (Figure 5c and Figure S23), 
which resulted in reduced line width of the ${ }^{1} \mathrm{H}$ resonance for the ligand and an increased intensity for the $-\mathrm{OH}$ species. Both NMR spectroscopic experiments indicate that $\mathrm{Cu}$ (II) is not responsible for the line broadening observed upon the adsorption of $\mathrm{NO}_{2}$ but is a result of increased structural heterogeneity that facilitates the adsorption of $\mathrm{NO}_{2}$ onto the MOF interior and, in addition, $\mathrm{NO}_{2}$ binds to $-\mathrm{OH}$ and $\mathrm{Cu}$ sites, as revealed by the DRIFTS experiments. Interestingly, the increased resolution in the ${ }^{1} \mathrm{H}$ Hahn-echo MAS NMR spectrum of $\mathrm{NO}_{2}$-adsorbed $\mathrm{Cu} / \mathrm{UiO}-66$ (Figure $5 \mathrm{~d}$, bottom) reveals a high-shifted ${ }^{1} \mathrm{H}$ signal at $\delta\left\{{ }^{1} \mathrm{H}\right\} \sim 9.6 \mathrm{ppm}$, along with adsorbed bulk water at $\delta\left\{{ }^{1} \mathrm{H}\right\} \sim 5.3 \mathrm{ppm}$; it should be noted that this experiment is not quantitative. Upon the removal of $\mathrm{NO}_{2}$, the high-shifted ${ }^{1} \mathrm{H}$ signal and that of bulk water mostly disappear, while low-shifted $-\mathrm{OH} / \mathrm{OH}_{2}$ signals emerge (Figure 5d, top). The high-shifted ${ }^{1} \mathrm{H}$ signals (at $\delta$ $\left.\left\{{ }^{1} \mathrm{H}\right\} \sim 9.6 \mathrm{ppm}\right)$ can be ascribed to nitric/nitrous acid species. ${ }^{43,44}$ The $2 \mathrm{D}{ }^{1} \mathrm{H}$ homonuclear dipolar correlation spectrum of $\mathrm{Cu} / \mathrm{UiO}-66$ with $\mathrm{NO}_{2}$ (Figure S24) displays correlations between these acidic protons and protons of the ligand but not with water or defect protons. Notably, this indicates that an intermediate in the reduction of $\mathrm{NO}_{2}$ by $\mathrm{Cu}$ / $\mathrm{UiO}-66$ could be nitric/nitrous acid and that it adsorbs, most likely through hydrogen-bonding, to the ligand. This is corroborated with data from ${ }^{13} \mathrm{C}$ MAS NMR (Figure S25), which shows a shift in the carboxylate ${ }^{13} \mathrm{C}$ signal upon adsorption of $\mathrm{NO}_{2}{ }^{45}$

\section{CONCLUSIONS}

The development and application of new efficient technologies to enable the precise identification of single metal sites and their roles in catalysis are important targets. We have undertaken a comprehensive study of the local structure of the single-atom $\mathrm{Cu}$ sites in $\mathrm{Cu} / \mathrm{UiO}-66$, thus enabling elucidation of their critical role in the reduction of $\mathrm{NO}_{2}$. The combination of the single-atom catalyst $\mathrm{Cu} / \mathrm{UiO}-66$ and NTP leads to the direct decomposition of $\mathrm{NO}_{2}$ to $\mathrm{N}_{2}$ at room temperature. $\mathrm{Cu} / \mathrm{UiO}-66$ exhibits unprecedented catalytic efficiency and excellent stability. Atomically dispersed $\mathrm{Cu}$ sites anchored at the defect sites of the UiO-66 scaffold prevents the $\mathrm{Cu}$ atoms from migrating and sintering during reaction and are responsible for the superior catalytic performance. In $\mathrm{Cu} / \mathrm{UiO}-66$, the adsorption of $\mathrm{NO}_{2}$ occurs at the $\mathrm{Cu}$ and hydroxyl sites, forming nitro/nitrate and related intermediates, which readily transform on activation with NTP to regenerate accessible active sites on the catalyst surface. The excellent catalytic performance of $\mathrm{Cu} / \mathrm{UiO}-66$ originates from the synergistic effects between atomically dispersed $\mathrm{Cu}$ sites and the framework porosity, providing multiple binding sites to promote the adsorption and conversion of $\mathrm{NO}_{2}$. New controllable deNO$_{x}$ processes integrating single-atom catalysts with a NTP technique could provide an efficient solution to the mitigation of $\mathrm{NO}_{x}$ emissions.

\section{ASSOCIATED CONTENT}

\section{SI Supporting Information}

The Supporting Information is available free of charge at https://pubs.acs.org/doi/10.1021/jacs.1c03036.

Additional experimental details, PXRD and NPD data, $\mathrm{N}_{2}$ adsorption isotherms, TGA plots, SEM and HAADFSTEM images, EPR, UV-Vis, solid-state NMR, XPS,
Auger and DRIFTS spectra, Figures S1-S25 and Tables S1-S6 (PDF)

\section{Accession Codes}

CCDC 2054313 and 2054314 contain the supplementary crystallographic data for this paper.

\section{AUTHOR INFORMATION}

\section{Corresponding Authors}

Daniel Lee - Department of Chemical Engineering and Analytical Science, University of Manchester, Manchester M13 9PL, United Kingdom; (1) orcid.org/0000-0002-10150980; Email: daniel.lee@manchester.ac.uk

Martin Schröder - Department of Chemistry, University of Manchester, Manchester M13 9PL, United Kingdom; ○ orcid.org/0000-0001-6992-0700; Email: M.Schroder@ manchester.ac.uk

Sihai Yang - Department of Chemistry, University of Manchester, Manchester M13 9PL, United Kingdom; ○ orcid.org/0000-0002-1111-9272; Email: Sihai.Yang@ manchester.ac.uk

\section{Authors}

Yujie Ma - Department of Chemistry, University of Manchester, Manchester M13 9PL, United Kingdom

Xue Han - Department of Chemistry, University of Manchester, Manchester M13 9PL, United Kingdom

Shaojun Xu - Department of Chemistry, University of Manchester, Manchester M13 9PL, United Kingdom; UK Catalysis Hub, Research Complex at Harwell, Rutherford Appleton Laboratory, Harwell OX11 OFA, United Kingdom; School of Chemistry, Cardiff University, Cardiff CF10 3AT, United Kingdom; (1) orcid.org/0000-0002-8026-8714

Zi Wang - Department of Chemistry, University of Manchester, Manchester M13 9PL, United Kingdom

Weiyao Li - Department of Chemistry, University of Manchester, Manchester M13 9PL, United Kingdom

Ivan da Silva - ISIS Facility, STFC Rutherford Appleton Laboratory, Chilton, Oxfordshire OX11 OQX, United Kingdom; (1) orcid.org/0000-0002-4472-9675

Sarayute Chansai - Department of Chemical Engineering and Analytical Science, University of Manchester, Manchester M13 9PL, United Kingdom

Yichao Zou - Department of Materials, University of Manchester, Manchester M13 9PL, United Kingdom

Marek Nikiel - Department of Materials, University of Manchester, Manchester M13 9PL, United Kingdom

Pascal Manuel - ISIS Facility, STFC Rutherford Appleton Laboratory, Chilton, Oxfordshire OX11 OQX, United Kingdom

Alena M. Sheveleva - Department of Chemistry, University of Manchester, Manchester M13 9PL, United Kingdom; Photon Science Institute, University of Manchester, Manchester M13 9PL, United Kingdom

Floriana Tuna - Department of Chemistry, University of Manchester, Manchester M13 9PL, United Kingdom; Photon Science Institute, University of Manchester, Manchester M13 9PL, United Kingdom

Eric J. L. McInnes - Department of Chemistry, University of Manchester, Manchester M13 9PL, United Kingdom; Photon Science Institute, University of Manchester, Manchester M13 9PL, United Kingdom; @ orcid.org/0000-0002-4090-7040

Yongqiang Cheng - Neutron Scattering Division, Neutron Sciences Directorate, Oak Ridge National Laboratory, Oak 
Ridge, Tennessee 37831, United States; ㅇo이.org/00000002-3263-4812

Svemir Rudić - ISIS Facility, STFC Rutherford Appleton Laboratory, Chilton, Oxfordshire OX11 OQX, United

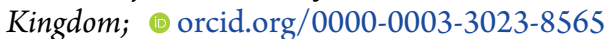

Anibal J. Ramirez-Cuesta - Neutron Scattering Division, Neutron Sciences Directorate, Oak Ridge National Laboratory, Oak Ridge, Tennessee 37831, United States

Sarah J. Haigh - Department of Materials, University of Manchester, Manchester M13 9PL, United Kingdom; (1) orcid.org/0000-0001-5509-6706

Christopher Hardacre - Department of Chemical Engineering and Analytical Science, University of Manchester, Manchester M13 9PL, United Kingdom; 이이.org/0000-0001-72566765

Complete contact information is available at:

https://pubs.acs.org/10.1021/jacs.1c03036

\section{Notes}

The authors declare no competing financial interest.

\section{ACKNOWLEDGMENTS}

The authors would like to thank the EPSRC (EP/I011870), the Royal Society and the University of Manchester for funding, and the EPSRC for funding of the EPSRC National EPR Facility at Manchester. This project has received funding from the European Research Council (ERC) under the European Union's Horizon 2020 research and innovation programme (grant agreement No 742401, NANOCHEM). This work was supported by the Henry Royce Institute for Advanced Materials, funded through EPSRC grants EP/ $\mathrm{R} 00661 X / 1, \mathrm{EP} / \mathrm{S} 019367 / 1, \mathrm{EP} / \mathrm{P} 025021 / 1$, and EP/ P025498/1. The authors are grateful to the STFC/ISIS Facility for access to Beamlines TOSCA and WISH. The UK $850 \mathrm{MHz}$ solid-state NMR Facility used in this research was funded by the EPSRC and BBSRC (contract reference EP/ T015063/1), as well as the University of Warwick including via part funding through Birmingham Science City Advanced Materials Projects 1 and 2 supported by Advantage West Midlands (AWM) and the European Regional Development Fund (ERDF). Collaborative assistance from the $850 \mathrm{MHz}$ Facility Manager (Dinu Iuga, University of Warwick) is acknowledged. A.M.S. was supported by the Royal Society Newton International Fellowship. Y.M. acknowledges financial support from the China Scholarship Council. Computing resources for neutron data analysis were made available through the VirtuES and the ICE-MAN projects, funded by Laboratory Directed Research and Development program and Compute and Data Environment for Science (CADES) at ORNL.

\section{REFERENCES}

(1) Qiao, B.; Wang, A.; Yang, X.; Allard, L. F.; Jiang, Z.; Cui, Y.; Liu, J.; Li, J.; Zhang, T. Single-atom catalysis of $\mathrm{CO}$ oxidation using $\mathrm{Pt}_{1} /$ $\mathrm{FeO}_{\mathrm{x}}$. Nat. Chem. 2011, 3, 634-641.

(2) Wang, A.; Li, J.; Zhang, T. Heterogeneous single-atom catalysis. Nat. Rev. Chem. 2018, 2, 65-81.

(3) Li, Z.; Ji, S.; Liu, Y.; Cao, X.; Tian, S.; Chen, Y.; Niu, Z.; Li, Y. Well-Defined Materials for Heterogeneous Catalysis: From Nanoparticles to Isolated Single-Atom Sites. Chem. Rev. 2020, 120, 623682.
(4) Zhang, T.; Walsh, A. G.; Yu, J.; Zhang, P. Single-atom alloy catalysts: structural analysis, electronic properties and catalytic activities. Chem. Soc. Rev. 2021, 50, 569-588.

(5) Wei, Y.-S.; Zhang, M.; Zou, R.; Xu, Q. Metal-Organic Framework-Based Catalysts with Single Metal Sites. Chem. Rev. 2020, 120, 12089-12174.

(6) Bavykina, A.; Kolobov, N.; Khan, I. S.; Bau, J. A.; Ramirez, A.; Gascon, J. Metal-Organic Frameworks in Heterogeneous Catalysis: Recent Progress, New Trends, and Future Perspectives. Chem. Rev. 2020, 120, 8468-8535.

(7) Babucci, M.; Guntida, A.; Gates, B. C. Atomically Dispersed Metals on Well-Defined Supports including Zeolites and MetalOrganic Frameworks: Structure, Bonding, Reactivity, and Catalysis. Chem. Rev. 2020, 120, 11956-11985.

(8) Han, A.; Wang, B.; Kumar, A.; Qin, Y.; Jin, J.; Wang, X.; Yang, C.; Dong, B.; Jia, Y.; Liu, J.; Sun, X. Recent Advances for MOFDerived Carbon-Supported Single-Atom Catalysts. Small Methods 2019, 3, 1800471.

(9) Zhang, E.; Wang, T.; Yu, K.; Liu, J.; Chen, W.; Li, A.; Rong, H.; Lin, R.; Ji, S.; Zheng, X.; Wang, Y.; Zheng, L.; Chen, C.; Wang, D.; Zhang, J.; Li, Y. Bismuth Single Atoms Resulting from Transformation of Metal-Organic Frameworks and Their Use as Electrocatalysts for $\mathrm{CO}_{2}$ Reduction. J. Am. Chem. Soc. 2019, 141, 16569-16573.

(10) Ji, P.; Song, Y.; Drake, T.; Veroneau, S. S.; Lin, Z.; Pan, X.; Lin, W. Titanium(III)-Oxo Clusters in a Metal-Organic Framework Support Single-Site Co(II)-Hydride Catalysts for Arene Hydrogenation. J. Am. Chem. Soc. 2018, 140, 433-440.

(11) Li, Z.; Schweitzer, N. M.; League, A. B.; Bernales, V.; Peters, A. W.; Getsoian, A. B.; Wang, T. C.; Miller, J. T.; Vjunov, A.; Fulton, J. L.; Lercher, J. A.; Cramer, C. J.; Gagliardi, L.; Hupp, J. T.; Farha, O. K. Sintering-Resistant Single-Site Nickel Catalyst Supported by Metal-Organic Framework. J. Am. Chem. Soc. 2016, 138, 1977-1982.

(12) Zhang, Y.; Jiao, L.; Yang, W.; Xie, C.; Jiang, H.-L. Rational Fabrication of Low-Coordinate Single-Atom Ni Electrocatalysts by MOFs for Highly Selective $\mathrm{CO}_{2}$ Reduction. Angew. Chem., Int. Ed. 2021, 60, 7607-7611.

(13) He, X.; Looker, B. G.; Dinh, K. T.; Stubbs, A. W.; Chen, T.; Meyer, R. J.; Serna, P.; Román-Leshkov, Y.; Lancaster, K. M.; Dincă, M. Cerium(IV) Enhances the Catalytic Oxidation Activity of SinglSite $\mathrm{Cu}$ Active Sites in MOFs. ACS Catal. 2020, 10, 7820-7825.

(14) Gong, Y. N.; Jiao, L.; Qian, Y.; Pan, C. Y.; Zheng, L.; Cai, X.; Liu, B.; Yu, S. H.; Jiang, H. L. Regulating the Coordination Environment of MOF-Templated SingleAtom Nickel Electrocatalysts for Boosting $\mathrm{CO}_{2}$ Reduction. Angew. Chem., Int. Ed. 2020, 59, 27052709.

(15) He, T.; Chen, S.; Ni, B.; Gong, Y.; Wu, Z.; Song, L.; Gu, L.; Hu, W.; Wang, X. Zirconium-Porphyrin-Based Metal-Organic Framework Hollow Nanotubes for Immobilization of Noble-Metal Single Atoms. Angew. Chem., Int. Ed. 2018, 57, 3493-3498.

(16) Abdel-Mageed, A. M.; Rungtaweevoranit, B.; Parlinska-Wojtan, M.; Pei, X.; Yaghi, O. M.; Behm, R. J. Highly active and stable single atom $\mathrm{Cu}$ catalysts supported by a metal-organic framework. J. Am. Chem. Soc. 2019, 141, 5201-5210.

(17) Trickett, C. A.; Gagnon, K. J.; Lee, S.; Gándara, F.; Bürgi, H.; Yaghi, O. M. Definitive molecular level characterization of defects in UiO-66 crystals. Angew. Chem., Int. Ed. 2015, 54, 11162-11167.

(18) Wu, H.; Chua, Y. S.; Krungleviciute, V.; Tyagi, M.; Chen, P.; Yildirim, T.; Zhou, W. Unusual and Highly Tunable Missing-Linker Defects in Zirconium Metal-Organic Framework UiO-66 and Their Important Effects on Gas Adsorption. J. Am. Chem. Soc. 2013, 135, 10525-10532.

(19) Garribba, E.; Micera, G. The determination of the geometry of $\mathrm{Cu}$ (II) complexes: An EPR spectroscopy experiment. J. Chem. Educ. 2006, 83, 1229-1232.

(20) Roessler, M. M.; Salvadori, E. Principles and applications of EPR spectroscopy in the chemical sciences. Chem. Soc. Rev. 2018, 47, 2534-2553.

(21) Ji, S.; Chen, Y.; Zhao, S.; Chen, W.; Shi, L.; Wang, Y.; Dong, J.; Li, Z.; Li, F.; Chen, C.; Peng, Q.; Li, J.; Wang, D.; Li, Y. Atomically 
Dispersed Ruthenium Species inside Metal-Organic Frameworks: Combining the High Activity of Atomic Sites and the Molecular Sieving Effect of MOFs. Angew. Chem., Int. Ed. 2019, 58, 4271-4275.

(22) Tang, Y.; Wei, Y.; Wang, Z.; Zhang, S.; Li, Y.; Nguyen, L.; Li, Y.; Zhou, Y.; Shen, W.; Tao, F. F.; Hu, P. Synergy of Single-Atom $\mathrm{Ni}_{1}$ and $\mathrm{Ru}_{1}$ Sites on $\mathrm{CeO}_{2}$ for Dry Reforming of $\mathrm{CH}_{4}$. J. Am. Chem. Soc. 2019, 141, 7283-7293.

(23) Ben Aissa, M. A.; Tremblay, B.; Andrieux-Ledier, A.; Maisonhaute, E.; Raouafi, N.; Courty, A. Copper Nanoparticles of Well-Controlled Size and Shape: A New Advance in Synthesis and Self-Organization. Nanoscale 2015, 7, 3189-3195.

(24) Devautour-Vinot, S.; Maurin, G.; Serre, C.; Horcajada, P.; Paula da Cunha, D.; Guillerm, V.; de Souza Costa, E.; Taulelle, F.; Martineau, C. Structure and Dynamics of the Functionalized MOF Type UiO-66 (Zr): NMR and Dielectric Relaxation Spectroscopies Coupled with DFT Calculations. Chem. Mater. 2012, 24, 2168-2177.

(25) Fu, Y.; Kang, Z.; Yin, J.; Cao, W.; Tu, Y.; Wang, Q.; Kong, X. Duet of acetate and water at the defects of metal-organic frameworks. Nano Lett. 2019, 19, 1618-1624.

(26) Valenzano, L.; Civalleri, B.; Chavan, S.; Bordiga, S.; Nilsen, M. H.; Jakobsen, S.; Lillerud, K. P.; Lamberti, C. Disclosing the Complex Structure of UiO-66 Metal Organic Framework: A Synergic Combination of Experiment and Theory. Chem. Mater. 2011, 23, $1700-1718$

(27) Parigi, G.; Luchinat, C. NMR Consequences of the NucleusElectron Spin Interactions. In Paramagnetism in experimental biomolecular NMR; Luchinat, C., Parigi, G., Ravera, E., Eds.; Royal Society of Chemistry: London, UK, 2018; pp 1-41.

(28) Peterson, G. W.; Mahle, J. J.; DeCoste, J. B.; Gordon, W. O.; Rossin, J. A. Extraordinary $\mathrm{NO}_{2}$ removal by the metal-organic framework UiO-66- $\mathrm{NH}_{2}$. Angew. Chem., Int. Ed. 2016, 55, 62356238.

(29) Kwak, J. H.; Tonkyn, R. G.; Kim, D. H.; Szanyi, J.; Peden, C. H. Excellent Activity and Selectivity of Cu-SSZ-13 in the Selective Catalytic Reduction of $\mathrm{NO}_{\mathrm{x}}$ with $\mathrm{NH}_{3}$. J. Catal. 2010, 275, 187-190.

(30) Jiang, H.; Zhou, J.; Wang, C.; Li, Y.; Chen, Y.; Zhang, M. Effect of Cosolvent and Temperature on the Structures and Properties of $\mathrm{Cu}-\mathrm{MOF}-74$ in Low-temperature $\mathrm{NH}_{3}$-SCR. Ind. Eng. Chem. Res. 2017, 56, 3542-3550.

(31) Gong, X.; Zhao, R.; Qin, J.; Wang, H.; Wang, D. Ultra-efficient Removal of NO in a MOFs-NTP Synergistic Process at Ambient Temperature. Chem. Eng. J. 2019, 358, 291-298.

(32) Wang, T.; Liu, H.; Zhang, X.; Guo, Y.; Zhang, Y.; Wang, Y.; Sun, B. A plasma-assisted catalytic system for NO removal over $\mathrm{CuCe} / \mathrm{ZSM}-5$ catalysts at ambient temperature. Fuel Process. Technol. 2017, 158, 199-205.

(33) Xu, S.; Han, X.; Ma, Y.; Duong, T. D.; Lin, L.; Gibson, E. K.; Sheveleva, A.; Chansai, S.; Walton, A.; Ngo, D.; Frogley, M. D.; Tang, C. C.; Tuna, F.; McInnes, E. J. L.; Catlow, C. R. A.; Hardacre, C.; Yang, S.; Schröder, M. Catalytic decomposition of $\mathrm{NO}_{2}$ over a copperdecorated metal-organic framework by non-thermal plasma. Cell Rep. Phys. Sci. 2021, 2, 100349.

(34) Wikstrom, L. L.; Nobe, K. Catalytic dissociation of nitrogen dioxide. Ind. Eng. Chem. Process Des. Dev. 1965, 4, 191-195.

(35) Wang, D.; Zhang, L.; Kamasamudram, K.; Epling, W. S. In SituDRIFTS Study of Selective Catalytic Reduction of $\mathrm{NO}_{x}$ by $\mathrm{NH}_{3}$ over Cu-Exchanged SAPO-34. ACS Catal. 2013, 3, 871-881.

(36) Zhang, Y.; Peng, Y.; Li, K.; Liu, S.; Chen, J.; Li, J.; Gao, F.; Peden, C. H. F. Using Transient FTIR Spectroscopy to Probe Active Sites and Reaction Intermediates for Selective Catalytic Reduction of $\mathrm{NO}$ on $\mathrm{Cu} / \mathrm{SSZ}-13$ Catalysts. ACS Catal. 2019, 9, 6137-6145.

(37) Sjövall, H.; Fridell, E.; Blint, R. J.; Olsson, L. Identification of adsorbed species on Cu-ZSM-5 under $\mathrm{NH}_{3}$-SCR conditions. Top. Catal. 2007, 42, 113-117.

(38) Wright, A. M.; Sun, C.Y.; Dincă, M. Thermal cycling of a MOFbased NO disproportionation catalyst. J. Am. Chem. Soc. 2021, 143, 681-686.

(39) Schneider, J. L.; Carrier, S. M.; Ruggiero, C. E.; Young, V. G.; Tolman, W. B. Influences of Ligand Environment on the
Spectroscopic Properties and Disproportionation Reactivity of Copper-Nitrosyl Complexes. J. Am. Chem. Soc. 1998, 120, 1140811418.

(40) Moreno-González, M.; Millán, R.; Concepción, P.; Blasco, T.; Boronat, M. Spectroscopic Evidence and Density Functional Theory (DFT) Analysis of Low-Temperature Oxidation of $\mathrm{Cu}^{+}$to $\mathrm{Cu}^{2+} \mathrm{NO}_{x}$ in Cu-CHA Catalysts: Implications for the SCR-NOx Reaction Mechanism. ACS Catal. 2019, 9, 2725-2738.

(41) Kalita, A.; Kumar, P.; Mondal, B. Reaction of a copper(II)nitrosyl complex with hydrogen peroxide: putative formation of a copper(I)-peroxynitrite intermediate. Chem. Commun. 2012, 48, 4636-4638.

(42) Hahn, E. L. Spin echoes. Phys. Rev. 1950, 80, 580-594.

(43) Steinbeck, C.; Krause, S.; Kuhn, S. NMRShiftDB - constructing a free chemical information system with open-source components. J. Chem. Inf. Comput. Sci. 2003, 43, 1733-1739.

(44) Banfi, D.; Patiny, L. Resurrecting and processing NMR spectra on-line. Chimia 2008, 62, 280-281.

(45) Bignami, G. P. M.; Davis, Z. H.; Dawson, D. M.; Morris, S. A.; Russell, S. E.; McKay, D.; Parke, R. E.; Iuga, D.; Morris, R. E.; Ashbrook, S. E. Cost-effective ${ }^{17} \mathrm{O}$ enrichment and NMR spectroscopy of mixed-metal terephthalate metal-organic frameworks. Chem. Sci. 2018, 9, 850-859.

(46) Yu, L.; Zhong, Q.; Zhang, S. Research of Copper Contained SAPO-34 Zeolite for $\mathrm{NH}_{3}$-SCR $\mathrm{DeNO}_{x}$ by Solvent-Free Synthesis with Cu-TEPA. Microporous Mesoporous Mater. 2016, 234, 303-309.

(47) Park, J. H.; Park, H. J.; Baik, J. H.; Nam, I. S.; Shin, C. H.; Lee, J. H.; Cho, B. K.; Oh, S. H. Hydrothermal Stability of Cu-ZSM-5 Catalyst in Reducing $\mathrm{NO}$ by $\mathrm{NH}_{3}$ for the Urea Selective Catalytic Reduction Process. J. Catal. 2006, 240, 47-57.

(48) Jiang, H.; Wang, S.; Wang, C.; Chen, Y.; Zhang, M. Selective Catalytic Reduction of $\mathrm{NO}_{x}$ with $\mathrm{NH}_{3}$ on Cu-BTC-derived catalysts: influence of modulation and thermal treatment. Catal. Surv. Asia 2018, 22, 95-104.

(49) Peng, B.; Feng, C.; Liu, S.; Zhang, R. Synthesis of $\mathrm{CuO}$ Catalyst Derived from HKUST-1 Temple for The Low-Temperature $\mathrm{NH}_{3-}$ SCR Process. Catal. Today 2018, 314, 122-128. 